\title{
Las marcas icónicas: ejemplo de deriva semántica
}

\author{
Gérald MazzaLovo \\ Grupo de Estudios de Semiótica de la Cultura (GESC) \\ Traducción de Eva Aladro Vico
}

(Abstracts y palabras clave al final del artículo)

Recibido: 13 de julio de 2014

Aceptado: 18 de julio de 2014

La vida del lenguaje es un espejo de la nuestra. Asistimos, desde hace varios años, a una moda frenética por el sustantivo "icono", y sobre todo de su adjetivo "icónico", tanto en las lenguas latinas como en la anglosajona. La encontramos en numerosos ámbitos de la comunicación y del consumo. Los iconos están omnipresentes en las múltiples pantallas digitales que acompasan nuestra vida cotidiana, como interfaces funcionales que activan las aplicaciones o las funciones. Los emoticonos, esas caritas redondas y amarillas que se supone representan toda la panoplia de emociones humanas mediante gestos y accesorios, son un ejemplo palmario de esto mismo.

Esas dos formas verbales disfrutan de un verdadero efecto de moda. Se utilizan directamente para nombrar numerosas actividades tan diversas como las marcas de moda (Icon Barcelona), los grupos de danza (Iconic Boyz), las cadenas de bares (Iconic bars), las marcas de cascos para moto (Icon Helmet), las escuderías (Icon), las revistas (Icon). Sirven sobre todo para calificar numerosas realidades: icono cultural, icono sexual, icono pop, iconos del verano, etc. El adjetivo se aplica a productos (Zippo, Jeep, Harley Davidson, Coca-Cola...) personajes... y marcas.

Estamos en presencia de una evolución semántica ejemplar en su rapidez. La palabra "icono" designa originalmente una pintura religiosa de la Iglesia Ortodoxa. Hoy la palabra se aplica a toda realidad (objeto, persona, organización, institución...) que simbolice valores y que sea reconocida por un cierto número de personas. Este texto es una reflexión sobre dicha evolución.

\section{EL SENTIDO ORIGINAL: EL ICONO RELIGIOSO}

Etimológicamente la palabra proviene del griego "eikon" que significa imagen, estatua, retrato. El Tesoro de la Lengua Francesa Informatizado ${ }^{1}$ da esta definición:

1 (www.atilf.atilf.fr). 
"En la Iglesia Ortodoxa, pintura religiosa sobre una tabla de madera, a menudo realzada con metal precioso o pedrería, dotada de valor simbólico y sagrada". La mayor parte de los iconos son pinturas, mosáicos o esmaltes en dos dimensiones. No son simplemente representaciones de temas religiosos, sino representaciones con significados religiosos. Ofrecen una visión del Reino de Dios. Tradicionalmente se las considera ventanas a un mundo divino que invitan al espectador a una experiencia espiritual.

\section{LOS NUEVOS SIGNIFICADOS}

Ante la profusión de usos actuales, hemos escogido dos nuevos usos emblemáticos: las marcas-iconos y los ídolos-iconos.

\section{MARCAS-ICONOS}

Uno de los autores clave en la promoción de esta expresión es el profesor Douglas B. Holt, titular de la Cátedra de Márqueting de L'Oréal en la Universidad de Oxford, quien en 2004 publica la obra titulada How Brands become Icons: The Principles of Cultural Branding ${ }^{2} \mathrm{El}$ título y el subtítulo indican inmediatamente que el branding cultural se ve implicado de manera significativa en el proceso de acceso al status de marca-icono. Tras haber reconocido que los iconos culturales dominan nuestro mundo, el autor se refiere a la definición dada por el Oxford English Dictionnary3: "una persona, una cosa considerada un símbolo representativo de una cultura o de un movimiento; una persona o una institución digna de admiración o respeto". El autor identifica esos iconos culturales con símbolos ejemplares aceptados por la sociedad (o por una parte significativa de la misma) como expresión sintética de ideas o valores importantes.

Holt juiciosamente nos procura un glosario de los términos clave de su enfoque:

- Una marca icónica es una marca de identidad cuyos valores identitarios se aproximan a los de un icono cultural.

- Una marca de identidad es una marca que los consumidores aprecian principalmente por sus valores identitarios.

- Los valores identitarios son aquellos expresados por una marca que pueden contribuir a la expresión de un individuo.

\footnotetext{
2 Traducción Cómo se convierten en iconos las marcas: los principios del branding cultural.

3 Version original: "A person or thing regarded as a representative symbol especially of a culture or a movement; a person or an institution considered worthy of admiration or respect."
} 
La adhesión de los consumidores a los valores propuestos por la marca se hace de diversas maneras. Sea porque son valores compartidos pues ya han sido adoptados, como por ejemplo un estilo de vida propuesto por la marca y ya practicado por el consumidor; sea que son valores descubiertos por el consumidor que comienza a desearlos. Podemos sintetizar el vocabulario del autor resumiendo simplemente que una marca-icono es un icono cultural, un símbolo de valores identitarios a los que los consumidores pueden adherirse.
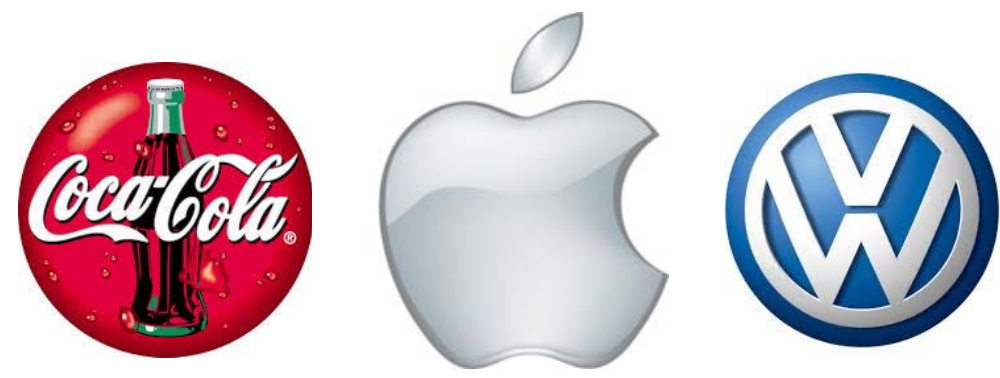

Ejemplos de marcas-iconos según Holt

\section{ÍDOLO-ICONO}

La expresión "icono" se aplica actualmente a personajes famosos del espectáculo, la ciencia o incluso de la política. Marilyn Monroe, símbolo de belleza voluptuosa y frívola, de mujer ardiente y maltratada... y de muerte solitaria y misteriosa; James Dean símbolo de la juventud rebelde americana de los años $50 \ldots$ Sus vidas (y sobre todo su muerte) les une definitivamente no solo a la historia, sino también a los humores y sentimientos compartidos por ciertas generaciones en determinados momentos. La brevedad de su existencia (en muchos casos han desaparecido prematuramente) les confiere un status heróico y facilita esa adhesión a un período preciso ligado a una generación y a sus preocupaciones existenciales específicas, sean de naturaleza social (guerra de Vietnam) o individual (angustia existencial, consumo de drogas...). Jimmy Hendrix, Janis Joplin, Elvis Presley, Grace Kelly, son algunos ejemplos...

La palabra "ídolo" sería mucho más adecuada, pues estos personajes a menudo son objeto de un verdadero culto. Algunos de ellos acceden incluso a un status mítico, pues como todo mito, sus vidas son un relato (Barthes 1957) que ofrece oposiciones binarias relativas a los límites existenciales de la condición humana (Lévi-Strauss 1973) como el espacio, el tiempo, la naturaleza, el destino, el amor, el sexo, la muerte, etc.

Desgraciadamente, la mayoría de los actores no alcanzan el status simbólico que representa problemas generacionales o cuestiones eternas de la condición humana. Para ellos, la dimensión icónica queda fuera de su alcance. No se representan más que a ellos mismos como individuos, sin valores particulares, como los candidatos de telerrealidad. Son signos sin significado, característicos de la hiperrealidad descrita por Baudrillard (1985). Son simples "vedettes", bella metáfora de origen militar, en declive, igual que la palabra "estrella" o "star". 


\section{ICONO-IMAGEN, ICONO-MARCA E ICONO-ÍDOLO}

Estas tres expresiones se han escogido por su carácter emblemático de la evolución semántica. Son signos en el sentido semiótico del término, y poseen significante (invariantes estéticas) y significado (invariantes éticas).

El cuadro de abajo resume las características respectivas de los tres signos seleccionados que usan la palabra "icono". La paradoja radica en la variedad de realidades que los tres expresan. Difieren enormemente en numerosos planos, no solamente en sus manifestaciones, sino también en su estética, ética, utilidad y base convencional, etc. El espacio de este texto no permite ilustrar en detalle el cuadro comparativo. Anotaremos tan sólo que el gran salto entre la imagen religiosa y la marcaicono se lleva a cabo con el aumento de población que determina la base convencional que subyace a la función del símbolo. Aunque la religión ortodoxa tiene también vocación universal, las marcas-iconos están en general globalizadas y pueden vanaglorarse de una base mucho más numerosa que las reconoce como símbolos de valores específicos.

\begin{tabular}{|c|c|c|c|}
\hline & ICONO IMAGEN & ICONO MARCA & ICONO ÍDOLO \\
\hline \multicolumn{4}{|l|}{ Significante } \\
\hline -Manifestaciones & Pintura & $\begin{array}{l}\text { Entidades } \\
\text { múltiples y } \\
\text { complejas }\end{array}$ & Individuo \\
\hline -Estética & $\begin{array}{l}\text { Técnicas } \\
\text { figurativas } \\
\text { comunes del } \\
\text { género }\end{array}$ & $\begin{array}{l}\text { Invariantes } \\
\text { características de } \\
\text { la identidad de la } \\
\text { marca }\end{array}$ & $\begin{array}{l}\text { Físico de la } \\
\text { persona, obras } \\
\text { culturales a las } \\
\text { que se asocia }\end{array}$ \\
\hline $\begin{array}{l}\text { Significado } \\
\text {-Ética }\end{array}$ & $\begin{array}{l}\text { Valores } \\
\text { religiosos }\end{array}$ & $\begin{array}{l}\text { Valores } \\
\text { identitarios }\end{array}$ & Valores sociales \\
\hline $\begin{array}{l}\text { Base } \\
\text { convencional } \\
\text { del símbolo }\end{array}$ & $\begin{array}{l}\text { Decidido por una } \\
\text { élite religiosa y } \\
\text { reconocido por } \\
\text { los creyentes }\end{array}$ & $\begin{array}{l}\text { Decidido por los } \\
\text { gestores de la } \\
\text { marca y } \\
\text { reconocido por el } \\
\text { mercado }\end{array}$ & $\begin{array}{l}\text { Reconocido por } \\
\text { los fans }\end{array}$ \\
\hline $\begin{array}{l}\text { Utilización por } \\
\text { los } \\
\text { responsables } \\
\text { del icono }\end{array}$ & $\begin{array}{l}\text { Promoción de la } \\
\text { religión e } \\
\text { invitación a la } \\
\text { oración }\end{array}$ & $\begin{array}{l}\text { Notoriedad e } \\
\text { identidad de } \\
\text { marca que } \\
\text { asegura } \\
\text { beneficios y } \\
\text { competitividad }\end{array}$ & $\begin{array}{l}\text { Status que } \\
\text { garantiza gloria y } \\
\text { fortuna }\end{array}$ \\
\hline $\begin{array}{l}\text { Utilización por } \\
\text { el espectador }\end{array}$ & $\begin{array}{l}\text { Oración, } \\
\text { recogimiento, } \\
\text { experiencia } \\
\text { mística }\end{array}$ & $\begin{array}{l}\text { Adhesión a los } \\
\text { valores } \\
\text { propuestos, } \\
\text { hedonismo }\end{array}$ & $\begin{array}{l}\text { Identificación } \\
\text { con el personaje, } \\
\text { y adhesión a los } \\
\text { valores } \\
\text { expresados }\end{array}$ \\
\hline $\begin{array}{l}\text { Sentimiento del } \\
\text { espectador con } \\
\text { relación al icono }\end{array}$ & Veneración & $\begin{array}{l}\text { Deseo de } \\
\text { posesión o de } \\
\text { experimentación }\end{array}$ & Admiración \\
\hline
\end{tabular}


La segunda gran diferencia es de naturaleza estética. La mayoría de los iconos tienen características plásticas (temas, tratamiento de la luz, perspectiva, colores, geometría, materiales, etc) comunes, mientras que las marcas tienen invariantes formales que son parte integrante de su identidad (Floch 1990, Mazzalovo 2012).

Estas tres expresiones tienen sin embargo en común su carácter simbólico peirciano 4 . En efecto, representan un significado reconocido convencionalmente por un público.

Siempre se da, en la actualidad, que el término icono se usa por la función representativa de toda entidad cuando dicha función es reconocida por el mayor número de personas.

\section{LAS PROBABLES RAZONES DE ESTA EVOLUCIÓN}

Una de las primeras razones reside en el proceso de inflación comentado por Gombrich (1994) que se propaga a cuestiones no solamente de naturaleza monetaria sino a dominios como la moda, el arte y también al lenguaje.

En un principio podemos imaginar la utilización de la metáfora para apropiarse de la dimensión espiritual del icono religioso que la palabra "símbolo" no posee. Gombrich señala ya expresamente a los publicistas y al mundo académico como autores responsables de esa carrera hacia el máximo énfasis expresivo. El deseo de atraer la atención hacia quien habla (las marcas) exacerba la utilización de énfasis semánticos y de usos a menudo inapropiados del vocabulario. Gombrich pone este fenómeno en evidencia como causa principal de la "corrupción del lenguaje". La audacia metafórica inicial se propaga entonces como una expresión de moda. El periodo posmoderno, en su mezcla de géneros y confusión de categorías se caracteriza pues por un uso intenso de la metáfora en el que el referente pertenece a dominios completamente ajenos a la significación del vocablo original.

La segunda razón de esta evolución se halla en el advenimiento de la sociedad de consumo. La deriva semántica, a la que conviene esa denominación en la medida en que provoca ambiguedad y polisemia, extiende la significación inicial reconocida por una minoría al reconocimiento de la gran mayoría. El proceso sigue la misma trayectoria que la economía, que se convierte en masiva en términos de producción, distribución y comunicación. Se tiende a lo universal por razones esencialmente económicas y el menor atisbo de notoriedad debe explotarse con fines financieros. El significado pasa pues de una base convencional restringida, limitada a los creyentes de una religión específica, a una base convencional que incluye al mayor número de personas. La evolución semántica de la palabra "icono" sigue una trayectora paralela a la de las masas urbanas contemporáneas.

${ }^{4}$ La clasificación de signos en Peirce se basa en la naturaleza de la relación entre significante y significado. El icono opera por similitud de hecho entre los dos planos. Por ejemplo, un dibujo figurativo que representa una casa, o una onomatopeya. Un índice es un signo cuyo significado está ligado al significante por un nexo de naturaleza causal o por contigüidad.. El humo es un índice del fuego. La tercera categoría del signo viene constituida por los símbolos en los que la relación es puramente arbitraria y convencional.

Se apreciará que para la marca-icono, la significación etimológica del símbolo, como pieza de un puzzle que significa la petenencia a un grupo específico es más actual ahora si cabe. 
La tercera razón se halla en la necesidad de lo sagrado y el rol social (e incluso espiritual) de las marcas en nuestro periodo posmoderno (Marrone 2007). Una vez que los grandes relatos han perdido una parte importante de su credibilidad, la gente se repliega hacia los pequeños relatos que proponen las marcas (Lyotard 1979). Efluvios de lo sagrado quedan adheridos a la palabra icono, incluso en el uso extenso que hoy prevalece, que inconscientemente atienden a una necesidad de espiritualidad no satisfecha. Encontramos además esta metáfora de referente religioso en la utilización de la palabra "ídolo" para los "ídolos-iconos".

En el proceso de expansión cuantitativa del significado, se pierde la dimensión plástica del icono, para concentrarse en la activación de la dimensión inteligible. Una oportunidad no aprovechada por las marcas hasta el presente. Situación paradójica cuando consideramos, que según la clasificación de los signos en Peirce, un signo es un icono si existe una relación de analogía o de semejanza entre significante y significado. No hay nada icónico en el sentido peirciano del término, en los iconos del siglo XXI.

\section{LA PERSPECTIVA INVERTIDA}

Hay una característica estética de los iconos religiosos que sin embargo podría interesar a las marcas que intentan por todos los medios establecer una relación de intimidad con sus consumidores (sobre todo las marcas de productos de consumo y servicios o bienes para la persona en general): es la perspectiva invertida.

Al contrario que la perspectiva lineal, que se introdujo en el siglo XIII, en la que el punto de fuga se halla siempre en un plano posterior al cuadro, para crear el artificio de profundidad y de realismo, la perspectiva invertida, técnica desconcertante para el ojo europeo moderno, renuncia a la ilusión de profundidad y coloca su punto de fuga delante de la superficie del cuadro, sobre el espectador.

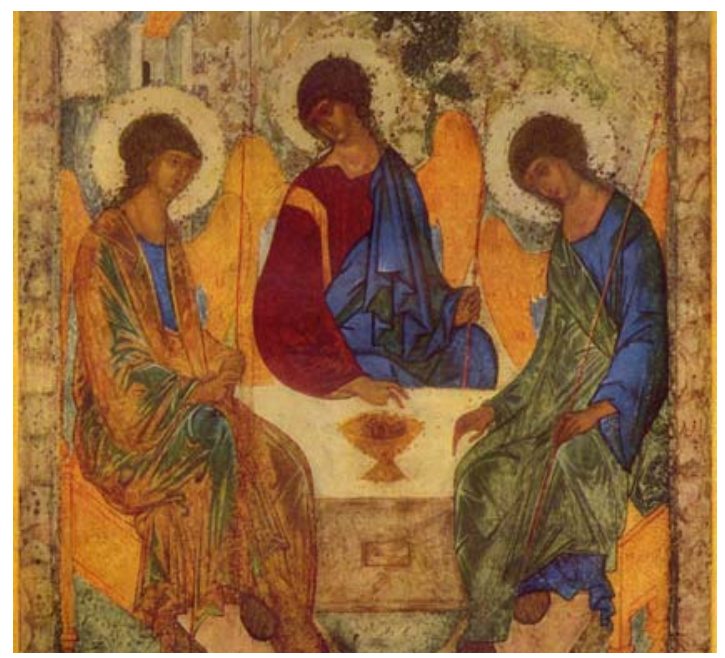

Andrei Rublev, icono de "La Trinidad", Moscú, hacia 1411. 
Esta perspectiva también llamada bizantina es bien visible cuando seguimos la línea de los dos tronos laterales del famoso Icono de la Trinidad de Rublev. Lo divino viene en busca del hombre e integra al espectador en la escena presentada por la pintura. Contrariamente a la pintura del Renacimiento, el icono no es una ventana sobre un mundo representado, sino un lugar de presencia. El mundo representado se abre para recibir al espectador. Es ese mundo el que es activo, y no el que lo contempla (Sendler 1981, citado por Floch y Collin 2009).

Es probablemente en la explotación de esas características plásticas del icono religioso, donde la metáfora inicial podría, si se trabajara del modo adecuado, desplegar toda su potencia. Todas las marcas sueñan con incluir a los consumidores en su mundo.

Gombrich ha comprendido bien el riesgo que ese proceso inflacionista de la utilización de expresiones cada vez más enfáticas, que "puede conducir a la consecuencia inesperada de rebajar simplemente el valor de lo que hacíamos anteriormente". ¿Se debilitaría la expresión "símbolo"?

Personalmente continúo evitando el uso de la expresión "marca-icono", y prefiero según el caso, o la expresión "marca-símbolo" o incluso "marca mítica", si se dan ciertas condiciones que trataré en otras publicaciones, aunque con ello pase por un iconoclasta fustigador de los efectos perversos de una evolución semántica que lleva a una pérdida de precisión del lenguaje, pero que es en cualquier caso irreversible. ¡Hay que vivir con el vocabulario de nuestro tiempo!

Hay sencillamente palabras a las que amamos más que a otras. Dejemos la última palabra a Gombrich: "no hay nada raro en que los enamorados del lenguaje sean también los enemigos de los neologismos", a los que podemos añadir, como objeto de la misma enemistad, las metáforas a las que califica de "pirotécnicas".

\section{BIBLIOGRAFÍA}

BAUdRILlard, Jean (1985), Simulacres et simulation, Editions Galilée, Paris.

BARTHES, Roland (1957), Mythologies, Editions du Seuil, Paris.

Floch, Jean-Marie (1990), Sémiotique, Marketing et Communication. Sous les Signes, les Stratégies, Presses Universitaires de France, Paris.

Floch, Jean-Marie; Collin, Jérôme (2009), Lecture de la Trinité de Roublev, Presses Universitaires de France, Paris.

Gombrich, Ernst H. (1994), Ideals \& Idols: Essays On Values in History and in Art, Phaidon Press, Londres.

Holt, Douglas H. (2004), How Brands become Icons: The Principles of Cultural Branding, Harvard Business School Publishing Corporation, Boston.

Lévi-Strauss, Claude (1973), Anthropologie Structurale, Plon Paris 1996.

LYOTARD, Jean-François (1979), La condition postmoderne, Editions de Minuit, Paris.

MARRone, Gianfranco (2007), Il discorso di marca. Modelli semiotici per il branding, Editori Laterza, Roma.

Mazzalovo, Gérald (2012), Brand Aesthetics, Palgrave Macmillan, Londres/Nueva York. PeIRCE, Charles S. (1931-1935), Collected Papers, Harvard University Press, Cambridge. SENDLER, Egon (1981), L'icône, image de l'invisible; Eléments de théologie esthétique et technique, Desclée De Brouwer, Paris. 


\title{
RESUMEN
}

Analizando las diferencias y desencuentros en las distintas acepciones del término « icono », en su deriva semántica en el mundo moderno, el autor revisa también las categorías de símbolo e ídolo y muestra sus conexiones con el mundo de las marcas, de los divos y figuras de referencia y de otros fenómenos de la comunicación actual. Presenta una ordenada división de los distintos tipos de funciones que cumplen los iconos, los símbolos y las demás categorías en estos tiempos, y analiza la célebre perspectiva inversa propia de los iconos religiosos ortodoxos. Por último, reflexiona sobre la inflación semántica característica de los procesos comunicativos en la modernodad, que desvalorizan el lenguaje.

Palabras clave: Iconos, idolos, imagen, marca, perspectiva inversa.

\section{Iconic Brands: an Example of Semantics Drift}

\begin{abstract}
Analisyng the differences and disruptions between the different meanings of the term «icon» and its semantic derive in modern world, the author reviews also cathefories such as symbol or idol, showing their connection with logos and marks, with «stars» and leaders in present mass communication. He exposes an ordered division of the different types and functions that the icons have, and analyses the famous inverse perspective used in religious icons from orthodox church. Finally, he reflects about the inflationist semantic process in communicative processes in the Modernity, that devaluate language.

Keywords: Icons, idols, Image, mark, inverse perspective.
\end{abstract}

\section{RÉSUMÉ}

Ce texte analyse les différences et déconnexions entre les divers sens du terme " icone » et la dérive sémantique qu'il a dans le temps moderne, en révisant des catégories comme symbole, idole, et nous montre leur rapport avec les phénomènes de la communication de masse comme les «stars » et les personnes de référence. Il expose un cadre ordonné des divers types et fonctions des icônes et analyse la bien connue perspective inverse utilisée dans les icônes religieux de l'église orthodoxe . Finalement, il réfléchit sur la dérive inflationniste des procès communicatifs dans la Modernité, que dévalue le langage.

Mots-clé: icones, idoles, symboles, marques, perspective inverse. 